GLOSSARY

\title{
Injury prevention: a glossary of terms
}

\author{
I Barry Pless, Brent E Hagel
}

J Epidemiol Community Health 2005;59:182-185. doi: 10.1136/jech.2003.017715

The main focus of this glossary is on injury prevention epidemiology and deals largely with terms about which there is some debate.

f

njury is a leading cause of death and disability for those under age $60 .{ }^{1}$ Relative to other major causes of death worldwide, road traffic injuries alone are the second or third leading causes from ages 5 to $44 .^{2}$ It is predicted that by 2020 the disability adjusted life years attributable to injuries will far exceed those from heart, cerebrovascuar disease, or respiratory disease. Despite this, until recently, injury as a public health problem has been largely ignored. Over the past decade in particular, however, there is growing recognition of the importance of the problem and the need for steps to address it. This is especially true in low income countries, where the cost of injuries may exceed the gross domestic product. One culmination of the growing interest is the World Health Organisations's current focus on road safety. ${ }^{2}$

The neglect is all the more striking given that many simple prevention measures are available but fail to be fully adopted. For example, road traffic and self inflicted injuries are the leading causes of injury death worldwide. ${ }^{1}$ Yet the use of child safety seats, safety belts, and a reduction of alcohol impaired driving, behaviours identified as "among the most important...to...reduce motor vehicle occupant injuries and deaths" still falls well short of the mark worldwide. Other examples include protective equipment in sports and pool fencing.

Thus, despite its evident importance, some injury prevention researchers have become accustomed to being viewed by colleagues in traditional epidemiological circles as newcomers at best and at worst as marginal members of the family. Readers who share either view may need to be reminded that injury prevention dates back to the 1940s with the biomechanical studies of DeHaven and later, Gordon. The field took its present form in the late 1960s when, Haddon, an epidemiologist, noted that the familiar triad in infectious disease epidemiology of agent, host, and environment was applicable to injuries. ${ }^{4}$ This model was later elaborated as a matrix that distinguished between primary (pre-event), secondary (event), and tertiary (post-event) prevention strategies. Recently, Runyan has proposed another dimension. ${ }^{5}$ In 1973 Haddon described 10 countermeasure strategies that amounted to a "unified theory" of prevention because all represented ways to limit harmful energy transfer. ${ }^{6}$
The main focus of the present paper is on injury prevention epidemiology. If it were only injury epidemiology, many terms in our lexicon would not be much different from their use in any other aspect of epidemiology. We would simply replace tuberculosis, cancer, or heart disease, for example, as the disease of interest, with injuries. When, however, the focus is on injury prevention, concepts and terms are used that are not only somewhat distinctive but occasionally contentious, both within and beyond the field. Hence, this paper deals largely with terms about which there is some debate.

\section{ACCIDENT VERSUS INJURY}

An excellent example is the word accident versus injury. Although some see no harm in viewing these words as synonymous, most deplore the use of the term "accident" except in one narrow sense. The reasoning is that the common meaning attached to the word "accident" is a random or chance event, and thus one that cannot be prevented. Extensive research has yielded solid evidence showing that most injuries are predictable and therefore preventable. Although the semantic distinction may be less in other languages, it seems appropriate to identify the issue in an English language journal. To examine the nuances in other languages is beyond our competence.

The word injury, as defined by Baker et al, will most often suffice: "Injury is the transfer of one of the forms of physical energy (mechanical, chemical, thermal, etc.) in amounts or at rates that exceed the threshold of human tolerance." It may also result from lack of essential energy such as oxygen (for example, drowning) or heat (for example, hypothermia). ${ }^{7}$

However, there may be times when "accident" seems appropriate-that is, to describe the primary event in a sequence that leads ultimately to injury if that event is genuinely not predictable. Nevertheless, readers are reminded that all $B M J$ specialty journals resolved to ban the word "accident" in any other context. ${ }^{8}$ This decision, announced in an editorial in the $B M J$, prompted an outpouring of letters to the editor. When the dust settled, the result was a draw with equal numbers of letter writers supporting this step towards enlightenment while all others were entirely condemnatory. The exchanges are worth reviewing: they are occasionally insightful and often amusing.

\section{INJURY PREVENTION VERSUS SAFETY PROMOTION}

Although to some it may appear self evident that the term safety is a direct reflection of successful injury prevention, just as health is in many 
respects a consequence of disease prevention, there is a respected view that argues otherwise. It maintains that the construct of "safety" and its application in policy and programmes is fundamentally different from injury prevention. It is considered broader with a strong subjective component and is intended to reflect feelings of security from threats of many kinds. ${ }^{9}$ Thus, subjective safety may be completely unrelated to "objective" safety as measured by a reduction in injuries (for example, perception of crime versus crime statistics). One result of this movement is the WHO inspired effort to create Safe Communities that are intended to reflect this philosophical or ideological distinction. The extent to which this has succeeded remains uncertain because the few such programmes that have been properly evaluated have yielded conflicting results. ${ }^{10}$

\section{INTENTIONAL VERSUS UNINTENTIONAL INJURY}

Unlike Gaul, which is divided into three parts, the world of injuries has two main divisions. The terms intentional and unintentional are self evident; the first includes homicide in all forms: war, violence, terrorism, spousal and child abuse as well as suicide. Unintentional includes all other forms of injury.

Even here, however, some see shades of grey between these seemingly distinct opposites. For example, an attempted suicide may be a gesture that has unexpectedly gone beyond what the victim intended. Or when foolish risk taking leads to injury as, for example, in extreme sports such activities might be viewed as intentional.

\section{INJURY CODING}

The most common injury coding system is the WHO International Classification of Diseases (ICD) that was developed to standardise the collection, coding, and reporting of mortality and morbidity statistics. ${ }^{11}$ For injuries, ICD uses two dimensions: the nature of injury (for example, fracture, dislocation), and the external cause code based on intent (for example, unintentional) and mechanism (for example, motor vehicle collision). Depending on the query, limitations of the ICD for injury research include the precedence of coding by intent over mechanism, the difficulty in determining intent, the burden placed on the history taker to allow sufficient detail for the use of an e-code, and that some injury diagnoses lie outside the standard "injury codes". ${ }^{11}$ These considerations may make it difficult to use ICD alone for research or prevention studies.

To address these concerns, an international working group-under the auspices of the WHO-developed the International Classification of External Cause of Injury Codes (ICECI) as a supplemental coding system for use with ICD $10 .{ }^{12}$ These codes allow for substantially greater detail on the circumstances surrounding the injury event and should aid researchers in understanding causes and evaluating preventive interventions. More detail on ICECI is available from their web site (http://www.iceci.org).

Many scales for coding severity have been developed. These are critical, not only for high quality research to control for confounding, but also for assessing the burden of injury. Alongside the AIS ${ }^{13}$ and ISS $^{14}$ there is the ICD based injury severity score (ICISS), which takes account of threat to life/ probability of death of a given injury. ${ }^{15} 16$

Coding reflects the sources of data and injury prevention research relies heavily (perhaps too heavily) on death or hospitalisation data. Many other sources are often available such as police records of road crashes, insurance companies' records for work related injuries, crime and social services statistics for cases of interpersonal violence.

\section{SURVEILLANCE}

The term surveillance is generally used in this field in much the same way as in other public health activities. There is, however, one important difference when compared with surveillance systems in infectious disease, for example. That difference involves response times or, more accurately, the time required for blips to be identified so that action can be taken. Furthermore, because few governments have strong commitments to injury prevention, and fewer still have national injury prevention programmes, the likelihood of action, fast or slow, is usually uncertain. Accordingly, some believe that injury surveillance that does not have the potential to identify new problems quickly, or for which there are few resources for action, is simply another form of data collection and not necessarily one that is more informative or more cost effective than periodic sample surveys.

\section{INJURY COUNTERMEASURES}

When considering preventive measures, injury epidemiologists invoke one or more of three main strategies-education, engineering, and enforcement. (Occasionally these are supplemented by evaluation, not a countermeasure as such, but it adds to the alliteration). However, Waller noted that the three fail to do justice to the full range of injury countermeasures in part because they are conceptually limited to the pre-event phase in Haddon's original matrix. ${ }^{17}{ }^{18}$ A more complete range of preventive options covering the pre-event, event, and post-event phases was described by Haddon in $1973^{6}$ and these are largely equivalent to the primary, secondary, and tertiary strategies described in the following section. Obviously the choice of the most promising option(s) is based largely on the context and nature of the injury in question.

\section{PRIMARY, SECONDARY, AND TERTIARY PREVENTION}

Primary prevention applies to the prevention of the initial event (the "accident") and in many instances this is not possible. To the extent to which such events are predictable, it is often the case that the only strategy that is conceivable, but rarely feasible and often undesirable, is to reduce or eliminate exposure to risk. Most prevention is at the secondary level, involving a range of strategies from product design to law enforcement. Last's defines tertiary prevention as "... measures ... to reduce or eliminate long-term impairment and disabilities, minimize suffering... and to promote ... adjustment to irremediable conditions. This extends the concept of prevention into the field of rehabilitation."18 19 The focus is not on preventing the injury but its consequences (for example, prompt transfer to minimise brain damage after head trauma). Some view this as beyond the remit of injury prevention, lying more squarely in the realm of injury control.

\section{Key points}

- Many of the terms used in injury prevention epidemiology are not used in the same way as they are in other branches of epidemiology.

- Not all the terms used are fully endorsed by everyone working in this field.

- This disagreement is especially prevalent with respect to concepts like safety, homoeostasis, and risk taking. 


\section{PASSIVE VERSUS ACTIVE MEASURES}

Nevertheless, the main focus for most in the field is secondary prevention, preferably using passive rather than active measures. ${ }^{20}$ However, even here, the extent to which a seemingly passive measure is truly that is often subtle. Smoke detectors were regarded as a sensible passive approach until the study by DiGuiseppi and Roberts showed that they were only effective if batteries remained charged and in place. ${ }^{21}$ Similarly, air bags are often cited as passive and for the most part they are unless they have been deliberately disconnected.

\section{INJURY CONTROL VERSUS INJURY PREVENTION}

The demarcation between these terms is subtle but important when politics, policy making, and resources are being considered. Injury prevention is largely a matter of primary and secondary prevention, especially secondary. Injury control, on the other hand, involves tertiary preventionthat is, what happens after the injury has occurred and which, if handled properly, might influence the eventual outcome (death, disability, etc). Injury control includes both prehospital care-that is, what ambulances and emergency medical services do-as well as emergency or casualty care and rehabilitation. The point of contention arises when most preventive resources are consumed by the hospital sector to improve emergency department or casualty services, leaving little for traditional public health initiatives.

\section{LEGAL LIABILITY AS A PREVENTIVE STRATEGY}

One distinctive element in injury prevention epidemiology is the potentially potent influence of court action as an adjunct to public policy promoting safety and responsibility, especially on the part of manufacturers. It is likely that many of the most important improvements were made in the wake of Ralph Nader's successful legal actions against manufacturers who, seemingly knowingly, continued to produce unsafe vehicles. ${ }^{22}$ More recently, cigarette manufacturers have been forced to acknowledge some share of responsibility for fires caused by cigarettes. ${ }^{23}$ This has prompted one state (New York) to require that manufacturers sell only self extinguishing ( so called "fire-safe") cigarettes.

Andrew McGuire, the director of the Trauma Foundation of the San Francisco General Hospital, a long time campaigner in this arena recently wrote: "I'm waiting for personal injury suits to be filed on behalf of burned plaintiffs since the ... companies have known how to make fire safe cigarettes for years. As Sue Baker et al showed years ago, nearly $1 / 3$ of the victims are not the smoker .... (they are the) babies, children and adults caught in the wrong place at the wrong time." ${ }^{\prime 24}$

Observers in less litigiously inclined countries than the US may read such statements with alarm but it is evident that many view litigation as a legitimate weapon. Certainly punishing manufacturers who violate existing safety regulations or standards would improve safety if the punishments were sufficient to deter future such behaviour. There are, however, limits even the most zealous would accept. One may be the example of an American 2 year old model and actor who cut his head at a playground and is seeking lost wages and other unspecified compensation from Greenwich, Connecticut. ${ }^{25}$ The suit demanded compensation for medical bills, pain, and suffering and a "lost wage amount due to his inability to audition or take modeling or commercial jobs while his head heals."

\section{RESEARCH DESIGNS}

Although no research designs are distinctive to this field, some can be used with particular advantage in injury prevention epidemiology. The case-control study has always been popular and recently, its variant, the case-crossover ${ }^{26}$ study has been shown to be especially promising in injury prevention research. The great strength of these designs for studies of injuries is based on their efficiency. Because injuries are acute events and, although common enough to be a problem, they are sufficiently rare to justify not wishing to assemble a cohort to follow up over time. Hence, selecting injured individuals and appropriate controls is far more feasible and, with attention to certain principles, ${ }^{27}$ an appealing option.

The randomised controlled trial (RCT) occupies the same position in injury prevention research as it does in most epidemiological studies. But it is difficult to apply in studies examining the efficacy of injury prevention strategies for several reasons. Blinding subjects to intervention (for example, smoke alarm installation) or control condition is all but impossible and the risk of contamination between study groups is arguably a more salient issue in injury research than in other areas of health research. Another difficulty arises in attempts to apply RCTs to community interventions. Although the benefits of community level interventions in this field are compelling, this design poses analytical challenges. One is that the unit of sampling and analysis must often be the community. ${ }^{28}{ }^{29}$ However, no injury related study of which we are aware has included a large enough number of communities, properly randomised, to achieve satisfactory levels of power. Advocates of the community approach argue that different standards and criteria should apply to such studies ${ }^{10}$ and although there is, no doubt, some sympathy for their predicament, the scientific challenges remain.

\section{RISK, EXPOSURE, AND RISK HOMOEOSTASIS}

Risk and exposure are as central to the epidemiology of injury prevention as they are to any other branch in the field. These terms are used both in the conventional sense and with some special nuances, however. For example, risk is often used as synonymous with "high risk" and in reference to subgroups in the population who have greater frequencies of injuries than others. Although careful researchers would not invoke this label without ensuring that the increased frequency does not simply reflect increased exposure, this is not true of everyone. Moreover, the leap is often made that by identifying high risk populations, the risk is modifiable and that the prevention effort is more efficient. Little thought is given to Rose $^{\prime} \mathrm{s}^{30}$ argument in favour of a population approach as a preferable alternative-one that in the long run is likely to be more feasible, more effective, and less costly.

Assessing exposure to risk-the appropriate denominator for most studies-is often bewilderingly complex in the case of injuries. Even for what seems to be a simple situation and for which measures are plentiful, for example, risk of a motor vehicle crash, there is little agreement about which denominator is most appropriate, for example, distance travelled,

\section{Policy implications}

Injury prevention epidemiology has become increasingly important because such a large proportion of all deaths and disability arise from this cause. An equally important reason for its importance to policy makers is the abundance of data showing how effective various preventive measures can be. The failure of policy makers to respond appropriately to these facts makes many working in this field suspicious that policy makers still regard injuries as accidents and not preventable in the same manner or to the same extent as other public health problems. 
trips taken, etc. But for other injuries such as drowning or burns, it is almost impossible to conceive of a denominator that truly reflects exposure to risk and that is feasible to measure.

Contentious as these may be, little in the field approaches the heat of the debate over the risk compensation or risk homoeostasis hypothesis. The problem begins because advocates of this notion, which suggests that safety measures are offset by greater risk taking to achieve a pre-determined innate risk taking homoeostatic balance, treat it as both proven and widely applicable. ${ }^{31} 32$ Those who oppose legislated or regulatory solutions to improve safety often use the hypothesis to support their objections. One prominent example is the case of bike helmets, which continues despite continued debate over the quality of evidence provided by risk compensation supporters. ${ }^{33-36}$

\section{EVIDENCE AND HEALTH POLICY}

In this field as in most others, the role of evidence in policy making is also a topic for debate. It is widely assumed that policy makers require evidence before they make decisions, and the buzz word, evidence based, is no stranger to injury epidemiology. Cynics, however, suspect that policy makers are inclined towards or against decisions with or without the evidence; if the two happen to be congruent, all well and good.

Although this argument is familiar, the emphasis by some injury prevention practitioners on policy making as a remedy introduces another element about which there is even less agreement: whether public support must reach a certain level before policy makers will be willing to act. The answer, if it were ever to come, is more likely to originate with political scientists than epidemiologists. This does not prevent some from plucking numbers out of the air and pronouncing, in effect, that legislation should not be introduced until $\mathrm{x} \%$ of the population is supportive. Little is said and apparently no thought given to the opposite situation in which far greater than $\mathrm{x} \%$ are supportive of, for example, tougher drunk driving laws, and yet policy makers refuse to act.

\section{SUMMARY}

As this glossary clearly suggests, injury prevention epidemiology is in a class of its own. It is not the same as injury epidemiology and also differs from other areas of epidemiology in many fundamental respects. We trust these differences do not continue to relegate those working in this challenging area, one that represents a still growing branch of epidemiology because of the rapidly increasing importance of injuries throughout the world, to lower status in the epidemiological hierarchy.

\section{ACKNOWLEDGEMENTS}

We thank our wives for tolerating our discussion of these terms when we should have been doing other spousal activities.

\author{
Authors' affiliations \\ I B Pless, Montreal Children's Hospital, Montreal, Canada \\ B E Hagel, Alberta Centre for Injury Control and Research, Department \\ of Public Health Sciences, University of Alberta, Edmonton, Canada \\ Funding: none. \\ Conflicts of interest: none declared.
}

\section{REFERENCES}

1 Peden M, McGee K, Krug E, eds. Injury: a leading cause of the global burden of disease, 2000. Geneva: World Health Organisation, 2002.

2 Peden M, Scurfield R, Sket D, eds, et al. World report on road traffic injury prevention. Geneva: World Health Organisation, 2004.

3 Task Force on Community Preventive Services. Recommendations to reduce injuries to motor vehicle occupants: increasing child safety seat use, increasing safety belt use, and reducing alcohol-impaired driving. Am J Prev Med $2001 ; 21: 16-22$.

4 Haddon W Jr. The changing approach to the epidemiology, prevention, and amelioration of trauma: the transition to approaches etiologically rather than descriptively based. Am J Public Health 1968;58:1431-8.

5 Runyan CW. Using the Haddon matrix: introducing the third dimension. Inj Prev 1998;4:302-7.

6 Haddon W Jr. Energy damage and the ten countermeasure strategies. J Trauma 1973;13:321-31.

7 Baker SP, O'Neill B, Ginsburg MJ, et al. The injury fact book. New York: Oxford University Press, 1992.

8 Davis RM, Pless IB. BMJ bans "accidents": accidents are not unpredictable. BMJ 2001;322:1320-1.

9 Nilsen P, Hudson DS, Kullberg A, et al. Making sense of safety: beyond injury prevention. Inj Prev 2004;10:71-3

10 Moller J. Reconsidering community-based interventions-balancing rigor and the real world. Inj Prev 2004;10:2-3.

11 Fingerhut LA, McLoughlin E. Classifying and counting injury. In: Rivara FP, ed. Injury control: a guide to research and program evaluation. Cambridge: Cambridge University Press, 2001.

12 International Classification of External Causes of Injury Coordination and Development Group. International Classifcation of External Causes of Injuries (ICECI) v. 1. la volume 1: tabular lists. Amsterdam: Consumer Safety Institute; Adelaide, AlHW National Injury Surveillance Unit, 2003.

13 Association for the Advancement of Automotive Medicine. The abbreviated injury scale, 1990 revision. Des Plaines, IL: AAAM, 1990.

14 Baker SP, O'Neill B. The injury severity score: an update. J Trauma $1976 ; 16: 882-5$.

15 Osler T, Rutledge R, Deis J, et al. ICSS: an international classification of disease-9 based injury severity score. J Trauma 1996;41:380-7.

16 Stephenson S, Henley G, Harrison JE, et al. Diagnosis-based injury severity scaling. Injury Research and Statistics Series Number 20. Adelaide: AlHW, 2003.

17 Haddon W Jr. A logical framework for categorizing highway safety phenomena and activity. J Trauma 1972;12:193-207.

18 Waller J. Injury control: a guide to the causes and prevention of trauma. Massachusetts: D C Heath, 1985.

19 Last JA. A Dictionary of epidemiology. Oxford: IEA, 1988.

20 Haddon W Jr. Strategy in preventive medicine: passive vs. active approaches to reducing human wastage. J Trauma 1974;14:353-4.

21 DiGuiseppi C, Roberts I, Wade A, et al. Incidence of fires and related injuries after giving out free smoke alarms: cluster randomised controlled trial. BMJ 2002;325:995

22 Nader R. Unsafe at any speed. The designed-in dangers of the American automobile. New York: Grossman Press, 1965.

23 Gunja M, Wayne GF, Landman A, et al. The case for fire safe cigarettes made through industry documents. Tobacco Control 2002;11:346-53.

24 The Trauma Foundation at San Francisco General Hospital. Update on the fire-safe cigarette-How New York State legislation will lead to the availability of fire-safe cigarettes across the nation. (http://www. If.org/tf/featured/8-2203firesafecig.html; 2004).

25 Cnews. 2-year-old model seeks lost wages in Connecticut playground mishap. (http://cnews.canoe.ca/CNEWS/WeirdNews/2003/12/26/297035ap.html)

26 Maclure $M$. The case-crossover design: a method for studying transient effects on the risk of acute events. Am J Epidemiol 1991;133:144-53.

27 Wacholder S, McLaughlin JK, Silverman DT, et al. Selection of controls in case-control studies. I Principles. Am J Epidemiol 1992;135:1019-28.

28 Cummings $\mathbf{P}$, Koepsell TD. Statistical and design issues in studies of groups. Inj Prev 2002;8:6-7.

29 Underwood MR, Carter YH. Randomised controlled trials in general practice: time for international collaboration. Inj Prev 1998;4:6-8.

30 Rose G. The strategy of preventive medicine. Oxford: Oxford University Press, 1992:95.

31 Wilde GJS. Target risk: dealing with the danger of death, disease and damage in everyday decisions. Toronto: PDE Publications, 1994.

32 Wilde GJS, Robertson LS, Pless IB. For and against: does risk homeostasis theory have implications for road safety. BMJ 2002;324:1149-52.

33 Adams J, Hillman M. The risk compensation theory and bicycle helmetsdissent and rebuttal. Inj Prev 2001;7:89-91.

34 Lardelli-Claret P, Luna-Del-Castillo JD, Jiménez-Moleón JJ, et al. Risk compensation theory and voluntary helmet use by cyclists in Spain. Inj Prev 2003;9:128-32.

35 Macpherson AK, Parkin PC, To TM. Reply to Robinson. [Letter]. Inj Prev 2003;9:380-1.

36 Robinson DL. Helmet laws and cycle use. [Letter]. Inj Prev 2003;9:380. 